PERCEPTIONS OF FACEBOOK AND TWITTER AS SOURCES OF HEALTH INFORMATION AMONG AFRICAN-AMERICAN WOMEN

A Thesis
presented to
the Faculty of the Graduate School
at the University of Missouri-Columbia
In Partial Fulfillment
of the Requirements for the Degree
Master of Arts
Dr. Margaret Duffy, Thesis Supervisor
DECEMBER 2017
bASEY ADAMS JONES


(C) Copyright by Casey Adams Jones 2017

All Rights Reserved 
The undersigned, appointed by the dean of the Graduate School, have examined the thesis entitled

\title{
PERCEPTIONS OF FACEBOOK AND TWITTER AS SOURCES OF HEALTH INFORMATION AMONG AFRICAN-AMERICAN WOMEN
}

\author{
presented by Casey Adams Jones,
}

a candidate for the degree of Master of Arts,

and hereby certify that, in their opinion, it is worthy of acceptance.

Dr. Margaret Duffy

Jon Stemmle

Dr. Glen Cameron

Dr. Joi Moore 


\section{DEDICATION}

To my God. For the breadth, length, height, and depth of love that covers me. For being a listening ear when I had doubts, fears or meltdowns that I kept inside. For being within me, so I could not fail (Psalm 46:5). For blessing me to follow an amazing experience at my first alma mater, N.C. State University, with another rewarding one at Mizzou. For giving me every resource I needed to graduate early. For just. being. God.

To my husband, Chris. For the many prayers. For frequent displays of love and patience through words and actions. For always having words of encouragement and ears that listened. For consistently being a real partner.

To my parents, Louis and Brenda. For the countless prayers and unconditional love since my birth. For instilling and inspiring character traits in me that have been my foundation for achieving countless goals. For setting me up for success in life.

To my father, Louis, and grandmother, Thelma. For your various battles with heart health-know that they were not in vain. You both inspired my research efforts.

To my parents-in-love, Michael and Patricia. For every prayer and word of encouragement. For the display of love towards me as your own child.

To the members of my "home team." For your words of encouragement when I needed them most. For being a source of inspiration to me by the life each of you leads.

To those my head cannot recall. For the positive vibes felt whether near or far.

To myself. For being determined and dedicated. For never wanting to quit. For finishing a 4-year degree program in 2.5 years while working full-time, owning a business, planning a wedding, moving halfway across the country and becoming a wife, to name a few. For having a strong finish because I had strong faith. 


\section{ACKNOWLEDGEMENTS}

To the admissions committee. For believing that I was a strong candidate for such a competitive program.

To my initial adviser, Sarah Smith-Frigerio. For believing I could finish the degree program early, amidst all of my obligations, and helping me create an aggressive course schedule to achieve that goal. For all the guidance, patience and support.

To my second adviser, Kathy Hodges. For graciously taking my many calls and emails, in efforts to be on top of things and not miss any deadlines. For all the guidance and support.

To one of the best professors I had, Ebony Reed. For giving me words of wisdom early in the program, which became part of my foundation for finishing well.

To the distinguished members of my thesis committee. For devoting time and wisdom towards helping improve not only my research, but also myself, as a scholar in the health communication space. For pushing me outside of my comfort level.

To the 23 women who participated in my focus groups. For showing up and showing out. Without your support and transparency, I would not have such diversity of voices from which to conduct and analyze my research, nor would I have this thesis.

To Diamond, Keshia and Meredith. For the bond I share with each of you as sisters in the journalism field. For celebrating milestones throughout the program with me. For coaching me through the challenges that come with being a "perfectionist.' For emphasizing, early on, the importance of doing research that impacts Black culture. 


\section{TABLE OF CONTENTS}

Acknowledgements ..................................................................... ii

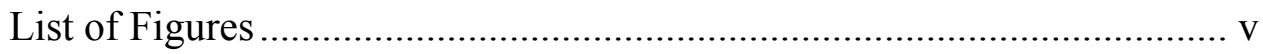

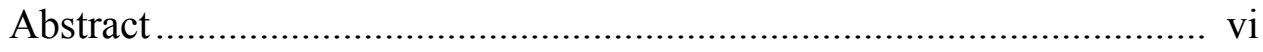

Chapter

1 Introduction.................................................................... 1

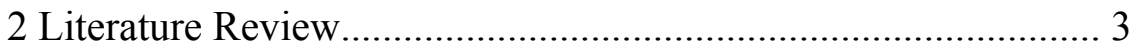

Media Systems Dependency Theory ............................ 12

Uses and Gratifications Theory ….............................. 15

Linking Frameworks .............................................. 15

Qualitative Methods and Research Questions ................ 16

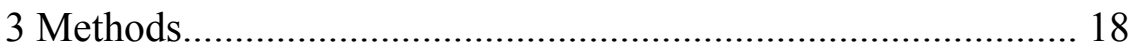

Focus Group Discussion Guide .................................... 22

Strategy for Analyzing Data ...................................... 24

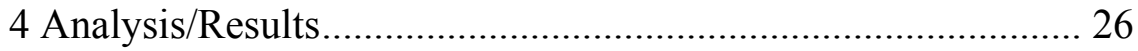


Perceptions of Facebook as a Source

Perceptions of Twitter as a Source....................................... 30

Facebook and Twitter Posts Prompting Research ............ 33

Advocating for One's Own Health .................................... 36

Fact Checking Health Information and Professionals ...... 37

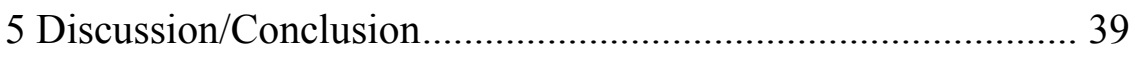

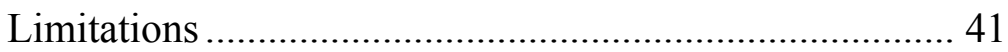

Areas for Further Research .............................................. 43

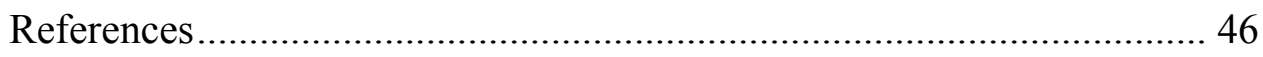

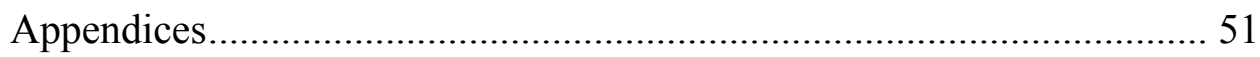




\section{LIST OF FIGURES}

Figure

Page

1. Selected Questions from the Focus Group

Discussion Guide

2. Participant Screening Survey via Qualtrics

3. Demographic Characteristics of African-American

Female Focus Group Participants

4. Heart Disease-Related Factors All Focus Group

Participants Learned from Facebook and Twitter........................ 54 


\title{
PERCEPTIONS OF FACEBOOK AND TWITTER AS SOURCES OF HEALTH
} INFORMATION AMONG AFRICAN-AMERICAN WOMEN

\author{
Casey Adams Jones \\ Dr. Margaret Duffy, Thesis Supervisor
}

ABSTRACT

Objective: The purpose of this study was to explore how African-American women perceive Facebook and Twitter as sources for information about heart disease. Methods: A qualitative study was conducted among 23 women between the ages of 18 and 70, who selfidentified as Black and female. Participants were recruited from both urban and rural cities. Data collected during each 60-minute or less focus group session was analyzed and grouped into key themes. Results: Among the Black women who participated in the research, findings indicated that Facebook and Twitter are perceived as credible sources of health information if the material shared comes from a health care professional or organization, or a friend speaking from a personal health experience. Credibility increased if information was presented by a person of color-particularly of the same race. Knowledge gained via social media was largely deemed to be the spring board for further research via a tool or website that is established within the health care industry. Participants also expounded upon the importance of one advocating for themselves in the doctor's office and fact checking health information and professionals. Conclusion: Health professionals may be able to more effectively communicate health information to Black women via Facebook and Twitter. Recommendations such as establishing credibility and using women of color in visuals are made that may assist in prompting health behavior changes.

Key words: Women, African American, health information seeking, social media, heart disease 


\section{Chapter 1: Introduction}

"Every 80 seconds, a woman dies from heart disease, and more than threequarters of these heart-related deaths are preventable" (Campbell, 2016, para. 1). However, a study by Sadler et al. (2005) revealed that 31 percent of African-American women did not deem heart disease as a top health threat to their population. Meanwhile, the number of individuals seeking health information has drastically increased over the past decade (Chisolm \& Sarkar, 2015). Approximately 70 percent of adults in the U.S. watch the news and 81 percent of them are sourcing these media outlets via the web, mobile applications, or social media (Mitchell, Gottfried, Barthel, \& Shearer, 2016).

How can a disease that is both preventable and curable claim the lives of so many women, when people are more actively seeking health care information than ever beforefrom multiple sources? It is evident that improvements in health communication must be made in order to increase awareness about cardiovascular disease and provide additional education tools for preventative and coping measures that can be taken.

My study will address questions of how African-American women perceive Facebook and Twitter as sources of information about heart disease. "According to U.S. Census Bureau estimates, African-American, Hispanic and Asian population growth will continue to outpace that of Whites by 2050" (Burrell, 2000, p. 18). Therefore, it becomes even more imperative that health organizations understand how to effectively communicate with underrepresented populations who will soon be the majority.

One of the greatest challenges with the distribution of health messages and campaigns is "reaching their audience with relevant, comprehensible, and effective 
messages to promote and sustain healthy behaviors amidst the vast amount of information they are exposed to, daily" (Rimal \& Adkins, n.d., p. 11). Studying underrepresented populations further extends the understanding of how dependent on media this niche audience is for health news.

Professionals in the journalism, communication, and health care fields have utilized mass media to increase public awareness of health challenges, such as heart disease, in efforts to encourage positive health behavior changes (Len-Ríos, 2009). The primary goal of such health campaigns is for each message to have the greatest exposure among its target audience and promote positive health behaviors (Rimal \& Adkins, n.d.).

The present research will investigate African-American women's perceptions of Facebook and Twitter as sources for heart disease information. What is revealed from my research may help identify the specific social media platforms most sourced by Black women and how they are viewed, in efforts to understand where health messages should go to be more effective in reach.

This thesis will explore the reliance of African-American women on not only mass media and the internet (or web), but Facebook and Twitter, as well. It will assess research that has explored where these individuals go when seeking health information and where they source health information on both traditional media platforms and newer technology (i.e., the internet, social media). Additionally, the thesis will take an in-depth look at the design and methods for conducting research in the quest of answering defined research questions; and conclude by noting research limitations and suggesting areas for further research. 


\section{Chapter 2: Literature Review}

Research from previous studies cited in this section will explore common definitions of source credibility and identify one to be referenced throughout this thesis. Findings will reveal whether African-American women depend on mass media for health information. They will also be analyzed for their demonstration of how, if at all, dependency has evolved to include the internet and social networking sites like Facebook and Twitter, which my research questions are seeking to answer.

Spence, Lachlan, Westerman, and Spates (2013) cite the definition of perceived source credibility: "[judgment] made by a perceiver ... concerning the believability of a communicator" (p. 4). The authors also mention three categories that determines whether a source is credible to a perceiver: if the source is trustworthy, if the source is an expert and would know factual information about the topic, and if the source has compassion for the perceiver. Additionally, van Zoonen and van der Meer (2015) layer the aforementioned definition with a note that the perceiver must also believe that the content being communicated is trustworthy or accurate, in order for it to be deemed as "credible."

Bates, Romina, Ahmed, and Hopson (2006) define source credibility as "a source that is a recognized expert, that keeps information current, and that has no competing interests in providing the information" (p. 2). For the present research, the combined definition as stated by Spence et al. (2013) and van Zoonen and van der Meer (2015) appears to be the most comprehensive. In addition to finding this explanation cited by the aforementioned authors, multiple studies including Ma and Atkin (2017) and Rains and 
Karmikel (2009) referenced it in their research related to understanding how the public perceives credibility of online health information.

Results from the Health Information National Trends Survey (HINTS) in 2011/2012 revealed that 77.6 percent of adults in the U.S. seek health information online, whether on behalf of others or themselves (McCarroll et al., 2014). The authors also noted that almost half of adolescent and adult internet users have an account set up on a social media platform inclusive of Facebook and Twitter, and that 15 percent of adult users access health care-related information from these mediums. Since these statistics were from 2011, yet were significant, I became intrigued to see how the top sourced platforms - Facebook and Twitter, were perceived among adults within my population of interest, African-American women.

In research by Paige, Krieger, and Stellefson (2017), findings showed that older adults (over age 50) trusted health information via Facebook the most and more AfricanAmericans than Caucasians rated Twitter as being credible sources of health information. It is important to note that the findings applied to a low eHealth literate population. The authors defined eHealth literacy as the level of "skills needed to seek, find, appraise, and evaluate health information from electronic sources to address health concerns and make health decisions" (p. 53).

Barthel, Shearer, Gottfried, and Mitchell (2015) conducted a survey to gauge the percentage of a sample population of 2,035 adults, age 18 or older, who were Facebook or Twitter users and what information they sourced from the respective platforms. At the time of the study, 63 percent of those surveyed reported using Facebook and Twitter as sources of news. According to the survey results, 63 percent of the Facebook news 
consumers were non-White and 64 percent of Twitter news consumers were non-White. Also, the authors found that utilizing Facebook and Twitter for health information, among other categories including entertainment, was more common in women than men.

Health communication researchers whose mission it is to reach underrepresented populations may need to send culturally relevant messages through diverse media channels including radio and television, according to Len-Ríos (2009). She noted that research shows mainstream and targeted media channels can be used to raise awareness among U.S. racial and ethnic populations about health issues and to encourage preventative behavior. Similarly, Lumpkins, Cameron, \& Frisby (2012) write: "Strategically positioned health information with appealing factors such as sociocultural factors, have the potential to increase awareness among the target population and eventually influence behavior" (p. 79).

Len-Ríos, Cohen, and Caburnay (2010) conducted a survey study involving 24 communities comprised of mostly women with an average age of 50 and a high school diploma. It was determined from their findings that African-Americans rely on and trust in newspapers that cater to their population specifically more than the general media, for health and cancer information.

Magazines are another print resource regularly used for health information by Black women. Lumpkins, Cameron, and Frisby (2012) noted that in their pilot study, which analyzed four mass magazines (Ms., Essence, Good Housekeeping, and Redbook) that target women, African-American women named this print medium as a trusted and popular source of health information. The analysis revealed that women's magazines frequently cover health issues and serve as a conduit of health information delivered to 
women in a way that is both appealing and entertaining. Researchers inferred that the increase of women's consciousness about their health could be attributed to an increase in health stories in the media (Lumpkins, Cameron, Frisby, 2012).

Research on urban African-American radio listeners supports the reliance on radio as a source of information. Not to be overlooked is Black-owned radio stations as a communication channel "with an established audience of African-American listeners" (Hall, Ashani Johnson-Turbes, \& Williams, 2010, p. 4). The authors analyzed several research articles related to stations with predominantly African-American audiences and the dissemination of health information through them and suggested radio as a notable resource for reaching this targeted population with health information. They stand behind this notion even though there has been significant attention given to new media such mobile phones, tablets, etc. Hall et al. (2010) cite data revealing that among urban African-Americans who depend on radio for news, facts and figures, "37 percent indicated that it is a favored source and 21 percent reported using ethnic radio for information in addition to mainstream sources" (p.1).

Beal's (2015) national survey found African-American women utilize search engines when seeking health information online (namely, stroke) and that they may not be able to discern the credibility of certain sites due to a gap in health literacy. However, her study lacked inclusiveness of African-American women who live in rural areas, do not attend a church predominantly of their same race, and may not have a link to stroke (i.e., they nor a loved one having been diagnosed).

In Beal's focus group sessions, Black women identified television programs as one of the top three resources used when seeking information on health care-related 
topics. She gathered from the data results that perhaps a public-access channel airing culturally relevant programming would be an effective way to reach AfricanAmerican women with information on health conditions. This option, along with group forums (i.e., local congregations hosting a watch party for its female membership then following it with an open discussion afterwards) and web-based education resources, was suggested as options for communicating health information to African-American women. Mass media outlets are not the only source of health information retrieval. A Pew Research Center (2017) national survey found that 90 percent of American adults use the internet, which is up from the 50 percent who reported using it in 2000. Access to the internet having increased over time has opened the door for social media and other online platforms to serve as growing sources for health information.

Laz \& Berenson's (2013) survey results found that “93 percent of White and Black women... used the internet while 74.5 percent of these internet users searched online for health information" (p. 257). Their research did not go in-depth to explore the types of websites visited, but rather confirmed whether the internet was used, where, and for how long.

Riffe et al. (2008) conducted research on people's dependency on the internet for a deeper dive into information on topics including health, science and business. Roughly half of the participants in their national survey noted using the web more than certain print outlets and friends or family for information related to personal health problems specifically. The authors cited the internet's search capabilities, which can provide comprehensive, specialized information, as being an enticing factor for its users. 
Chisolm and Sarkar (2015) analyzed a 2010 Pew Internet and American Life Health Tracking Survey on African-Americans obtaining health information via the internet and their findings support this medium as another regularly used source. The data showed that the use of the internet among African-Americans "has grown from 35 percent in June 2000 to 71 percent in August 2011” (p. 163), for reasons such as surfing the Web to find health information, jobs, civic and interpersonal interaction, or entertainment. They labeled internet-based health information as being of value among the Black population because of its potential to reduce communication barriers, improve relationships between social status and health, and support empowerment.

A study by Tustin (2010) looked at health information seeking behaviors and why people rely on the internet over their own health provider. Fifty-eight percent of survey participants who had been diagnosed with cancer chose the internet as their preferred source of health information over their oncologist. Tustin applied the media system dependency theory, citing "that individuals are in particular need of information in threatening conditions characterized by ambiguity" (p. 6). The findings revealed that cancer patients believed the accurate information about their condition and reassurance they sought were received in a timelier fashion via the internet. Also, Tustin noted mass media do not frequently cover specific cancer-related issues, so again, the internet is depended upon greater than traditional media channels and interpersonal networks like loved ones, doctors or nurses.

"Internet health information seeking is part of the larger construct of e-health use, defined as the use of health services and information disseminated through the internet and related technologies" (Chisolm \& Sarkar, 2015, p. 163). Health information provided 
via the web offers its viewers knowledge needed to improve self-care, to share learned information with others and receive support, as well as to learn more about their health. The perceived anonymity it offers makes this platform a top choice for detailed information on sensitive health topics. Accessing online health information also provides support in decision-making, including when to consult a health specialist and what treatment options to consider. Chisolm and Sarkar found that among African-Americans who already use the internet, those of a higher socioeconomic status and who are collegeeducated were significantly associated with increased odds of searching for health information online and socializing online. Their study was based off a survey of AfricanAmericans who only use the internet and email occasionally.

In a national survey conducted in 2013, more than three-fourths of respondents who sought health information online used a search engine instead of a dedicated health site (Pew Research Center, 2013). A disadvantage of using search engines is that consumers may lack skills to comb through the large number of results and assess the credibility of websites. This calls for a strategy to be created that can help develop wellprepared internet users.

Although the number of adults in the U.S. who use the web is significantly high, it is important to note that 13 percent of them do not (Anderson \& Perrin, 2016). The Pew Research study cited lack of interest, ease of use, and cost of acquiring and maintaining access as being among reasons reported by this group. More demographics about the group of non-internet users include having a residence in a rural area, being 65 years old or older (senior), making less than $\$ 30,000$ a year, and not having a high school diploma. 
Lachlan, Spence, Edwards, Reno, and Edwards (2014) make a connection between social media, another communication media outlet, and media dependency theory. The researchers affirm that particularly "when public health threats are impending, people can be expected to engage in specific information seeking patterns that are consistent with Media Dependency Theory" (p. 378). They suggest that the social media platform of public health organizations could be a top-sourced outlet if the public trusts the medium and receives information as quickly and thoroughly as possible.

"Nearly twice as many adults often get news online than get news in print" (Matsa \& $\mathrm{Lu}, 2016$, para. 2). The authors include websites, social media, and mobile applications in their definition of the term "online" and note that television is still a the most sourced channel for news information. Additionally, the survey found that social media was often sourced for news-particularly Facebook (66 percent of users) and Twitter (59 percent of users). Although this data is representative of a larger population base, African-American women were included in the sample, so this information is important to consider.

A few top areas of deficiency in research about Black women and social media platforms were how these, Facebook and Twitter, in particular, were perceived as providers of health information, ways they increased consumers' knowledge, how they help this population act on the information received, and how repeated exposure to messages over time can influence health behavior.

In southeast Ohio, Bates, Romina, Ahmed, and Hopson (2006) conducted a community-wide survey among residents of a large regional hub, and randomly assigned one of six messages about lung cancer prevention that was sourced from either a highly credible website or one with low- or no-credibility. Some participants were given the 
name of the information source, and some were not. The scholars found that sharing the source of information had little or no effect on how health information seekers perceived a message in comparison to one from a site not as credible. Their conclusion was that national organizations should find a way to brand themselves as highly credible sources so consumers will reference their website when seeking information about a healthrelated topic via a search engine.

Spence, Lachlan, Westerman, and Spates (2013) "examined how individuals make credibility judgments about health-related information from social media sites" (p. 1) through a 200-participant survey (African-American and Caucasian) from a convenience sample and snowball sample. They created two mock Facebook pages and pushed articles on cardiovascular disease, randomly assigning some to what appeared to be the page of a Black and a White person). Spence et al. cited credibility as an important prerequisite for persuasion. A notable portion of their speculation was that, overall, messages targeting African-Americans and delivered by the profile with the AfricanAmerican avatar thru a social networking site were perceived as more trustworthy. This is likely because they are delivering information to a community that impacts them, as well.

A focus group conducted by Rennis, McNamara, Seidel, and Shneyderman (2015) set out to understand the various reasons college students utilize the internet and discussions revealed the top categories to be-health care, self-care (fitness and wellness), to attain knowledge and be entertained. One point of concern mentioned by participants was the lack of a "one-stop shop" that could provide credible information from subject matter experts in the health realm. Students shared that they were often unsure how to assess the reliability of information they found online. The study confirmed that "access 
does not correlate with accurate use and evaluation of information” (p. 423). Exploring the perceptions of online health information is key to solving the puzzle of ways sites can market their credibility-what are consumers looking for as a confirmation that this resource can be trusted?

The literature review portion of this thesis assessed research that explored where individuals, notably African-American women, go when seeking health information, and how communication media (i.e., print, broadcast, internet, social media) are relied upon in their search. It reviewed studies on sources of health information accessed by Black women that focused on both traditional media platforms and newer technology (i.e., the internet, social media).

Thus, my two research questions are:

RQ1: How do African-American women perceive Facebook as a source for heart disease information?

RQ2: How do African-American women perceive Twitter as a source for heart disease information?

The research questions being explored are relevant to this thesis in that they seek to answer whether the reliance on social media outlets for health information exists, and if so, whether it applies to heart disease specific information and whether it is perceived as trustworthy. A recurrent theme of credibility was found in the previously mentioned studies, so I will incorporate it into my research efforts to see if I find similar results.

\section{Media Systems Dependency Theory}

Two theoretical constructs are appropriate to help understand how AfricanAmerican women deem certain sources of health information as trustworthy, particularly 
as it relates to heart disease. These frameworks are media systems dependency and uses and gratifications.

Media systems dependency was conceptualized by Ball-Rokeach and DeFleur (1976), who sought to define the level of effect mass media had on people and the world they lived in. The authors posited that the model "allows us to specify in a limited way when and why mass-communicated information should or should not have significant effects upon how audiences think, feel, and behave" (p. 19). They found that the "dependencies people have on media information are a product of the nature of the sociocultural system, category membership, individual needs, and the number and centrality of the unique information functions that the media system serves for individuals and for society" (p. 18-19). The theory assumes that individuals set out to achieve goals and are intentional about the media content they select and use.

Early research on media dependency explained how the power of media fluctuates. "It argued that dependency was a separate construct from simple media use (e.g., Do you read "X" newspaper?) and media exposure (e.g., How many days a week do you read "X" newspaper?)" (Len-Ríos, Cohen, \& Caburnay, 2010, p. 22). The researchers defined "dependency" by the reader's goals or motivation for using a certain medium. For example, when an African-American woman is educated on a topic or entertained because of a media product, she becomes reliant on it. The impacts of media messages were minimal to none when individuals were presented with information that they had enough knowledge about or were not seeking (Ball-Rokeach \& DeFleur, 1976).

Riffe, Lacy, \& Varouhakis (2008) offer a thorough and updated depiction of the theory, noting that it "later evolved into a more complex one that deals with the 
relationship between media and individuals at the micro level and media and social institutions at a macro level” (p. 2). Riffe et al. (2008) identify varying reasons why people depend on media including "for solitary play and social play; self- or socialunderstanding; and for action and interaction orientation" (p. 2).

Beaudoin's (2007) study used dependency theory in an observation of the effects of mass media during times of disaster-specifically, Hurricane Katrina, which occurred in New Orleans in 2006. It postulated "that in times of societal change and conflict, news use and its effects are intensified, with such effects culminating in behavior change" (Beaudoin, 2007, p.704). After Hurricane Katrina, media outlets effectively reached citizens of New Orleans to promote public safety behaviors. The public seemed to depend on news outlets for safety information and implement the campaign messages.

Kaye and Johnson (2016) focused their research efforts in the political space and used the media dependency theory to observe whether the public's dependence on various social media platforms (e.g., Facebook, blogs, and Twitter) could be motivated by the same factors as their reliance on mass media. They found that "the more satisfied users are with a medium, in this case social networking sites, the more they rely on it, and the more they rely on it the more satisfied they feel" (p. 15).

The aforementioned studies use media systems dependency to understand the reliance of the public on mass media to meet their goals of being educated on a topic, in order to understand and take action, as appropriate, per Riffe et al.’s (2008) interpretation. Each relate to my research area, as they explore what media outlets individuals rely on in the context of seeking information for understanding, as well as the 
level of dependency and data indicating that there is an established level of reliance for health information.

\section{Uses and Gratifications Theory}

Similarly, the uses and gratifications theory is centered on the user and posits that "individuals have particular needs that drive their selection of certain types of media" (Sundar \& Limperos, 2013, p. 506). It "addresses the psychological and social benefits that attract audiences to a variety of media types and contents" (Kim, Lee, Jo, Jung, \& Kang, 2015, p. 182). Before a dependency on media can be affirmed, this framework provides clarity on why various forms of media are initially chosen.

\section{Linking Frameworks: Media Dependency and Uses and Gratifications}

Ruggiero (2000) posited, “dependency on a medium or a message results when individuals either intentionally seek out information or ritualistically use specific communication media channels or messages" (p. 9). In other words, audience members actively seeking out information or routinely using certain media outlets to satisfy a need causes them to rely on that media. This combined approach further explained the effects of media on audiences.

Chen and Chang (2017) posit that both theories "are linked through audience "intentionality (believing in a medium and planning to use) and activity (choosing and depending on certain media)" (p. 814). To the authors, when an outlet satisfies a specific need (entertainment, information, etc.), one becomes increasingly reliant upon that source.

Media systems dependency describes how often a platform is used, while one's motivations for using it are explained by uses and gratifications. Because the core of my 
research is on frequent use of Facebook and Twitter, there was a heavier focus on the dependency than uses and gratifications. By researching African-American who seek out health information, specifically related to heart disease, via Facebook and Twitter and receive the gratification of locating it there and trusting the content, I expected to find that such prompts this population to utilize those social media platforms more frequently, thus influencing the level of dependency.

\section{Qualitative Methods and Research Questions, Correlation to Theory}

Qualitative methods "seek to make meaning... and calls attention to how groups use cultural artifacts to assert and sustain a version of reality, articulate and celebrate a sense of identity, and disguise or flaunt styles of domination or control" (Pauly, 1991, p. 2). I'm interested in exploring solutions to the challenge health organization face of needing to more effectively send messages to a targeted population of people via the right platform at the right time for the best effect-prompting preventative or coping health behaviors. This seemed fitting for qualitative research because I looked at how Black females "make meaning" of messages sent through mass media, the web, and social media, and gauged the level of reliance and influence.

Media systems dependency theory describes how often a platform is used, while one's motivations for using it are explained by the uses and gratifications framework. Again, to Chen and Chang (2017), when an outlet satisfies a specific need (entertainment, information, etc.), one becomes increasingly reliant upon that source.

Before a dependency on media can be affirmed, uses and gratifications provides clarity on why various forms of media are initially chosen. Using the qualitative method allowed for in-depth discussions to be conducted in order to understand how those within 
the African-American female population think (about various media platforms) and act (how messages on these platforms prompt an action).

Questions are best answered via this method because unstructured interviews, in particular, focus on the "complex voices, emotions, and feelings of interviewees, as well as the meanings within the words that are spoken" (Brennan, 2012, p. 28). These voices, emotions, and feelings have helped me better understand how Black women make meaning of mass media, web, and social media platforms that are used to retrieve health information and receive motivation for taking action such as preventative screenings, conversations with medical care providers, or changing diet and lifestyle habits. 


\section{Chapter 3: Methods}

The methodology section takes an in-depth look into the design and methods for conducting research in quest of answering the questions: how do African-American women perceive Facebook as a source for health information about heart disease and how do they perceive Twitter as a source for the same? Focus groups foster an environment where respondents can be probed to engage in more dialogue and provide clarity on anything misconstrued or not clear. This method also capitalizes on group interactions and is consistent with a culturally sensitive approach to research, which is fitting considering the topic and solicited audience.

According to Tillman (2002), when conducting research concentrated on the African-American population, cultural sensitivity comes into play when using "the cultural knowledge and experiences of researchers and their participants in the design of the research as well as in the collection and interpretation of data" (p. 3). By being an Black woman, studying other women in my demographic, I have intertwined such components into my studies. As such, I elected to pursue focus groups for my qualitative research efforts.

Tindall and Vardeman-Winter (2011) posit that "qualitative data inquiry... [are] appropriate to discover the meanings that women of color held regarding heart disease and to uncover the cultural factors that influence how women of color make meaning of health decisions" (p. 285). Understanding what perceptions of Facebook and Twitter African-American females have, as it relates to the trustworthiness of the platforms, led to knowing that they rely on social media, to an extent, when seeking information about 
cardiovascular disease. Messages sent through certain communication media are the types of messages that increase their knowledge and possibly bear influence on them to make positive health behavior changes. This research could lead to future studies that seek to determine the effectiveness of messages on Facebook and Twitter.

Gauging certain habits of consumers, as well as their usage of or feelings about an item, service, or platform/program are various examples of what can be learned via focus groups (Greenbaum, 1993). These "group interviews can provide another level of data gathering or a perspective on research problem not available via individual interviews" (Fontana and Frey, 1994, p. 365). A few other advantages the authors point out are that these sessions are inexpensive, offer flexibility in how the discussion is conducted, can excite respondents and prompt high engagement in the conversation that produces a wealth of data to be coded.

Rennis et al. (2015) conducted two focus groups comprised of six to eight people each, on the topic of how participants perceived the internet and motivations for using it. Their discussions, lasting approximately 90 minutes each, revealed health care to be among the top categories.

Bellinger, Millegan, and Abdalla (2015) also used the qualitative method and conducted three focus groups that explored "behavior, knowledge, and attitudes as influences on health decisions and preferences for cervical cancer prevention and control among African-American women in South Carolina" (p. 120). The authors asked 28 Black women ( 8 to 10 per group) who were between the ages of 18 and 70 a series of 17 questions over a 90-minute period. Eight of the participants were from rural areas and the 
remaining 20 were urban residents. This is similar to my focus group sessions, which were comprised of more women living in urban cities than rural.

Two focus groups conducted by Warren et al. (2010) had a total sample size of 18 African-American women varying in age between 19 and 60. The study evaluated the perception of the internet as a resource for health information among Black women, similar to my research efforts.

My aim to diversify the participant pool was driven by Anderson and Perrin's (2016) statement that "internet non-adoption is correlated to a number of demographic variables, including age, educational attainment, household income and community type" (para. 4). Such information will be helpful to know when analyzing my study results. Brennen (2012) states, "homogenous focus groups are more effective than heterogeneous groups" (p. 68). However, because of this, some perspectives can be overlooked. Berger (1998) suggests, "some diversity of opinion is helpful" (p. 67). For views within a focus group to be representative of the broader population of AfricanAmerican women, there must be diversity in the demographics of the study participants. A variety of age, area of residence, marital status, and educational level are enough to maintain effectiveness by keeping the sample size relatively homogenous.

The participant requirements for each of the three focus groups were inspired by Beal's (2015) study, which sampled 48 African-American women from predominantly Black churches varying in age from 36 to 88 in the qualitative study. There were 6 focus groups consisting of 6 to 10 women in each group and each session, where nine questions were asked, and it lasted 90 minutes. She recruited from two churches with a predominantly Black membership in an urban area and the sample was relatively 
homogenous regarding geography and religious affiliation. The breakdown of all participants was: average age- $68 ; 40$ percent married, 40 percent widowed, 20 percent single; and over half held a college degree.

I created a closed Facebook group recruiting 24 to 40 African-American women from ages 25 to 85 living in either a rural or urban area to participate in a focus group. In the group, I posted additional information about myself, my academic program, the study, and when focus groups would be conducted in three North Carolina cities-Greensboro, Durham, and Thomasville.

Greensboro and Durham are the third and fourth largest municipalities in North Carolina, while Thomasville sits in the 35th position (U.S. Census Bureau, 2016). Selecting a couple of top urban areas, as well as a rural area was another way to diversify the pool of participants, in addition to demographics such as age, income, education level, etc. These locations were also selected based on my familiarity with them and desire to have diversity in representation, as it relates to a city's population size and classification of urban or rural.

Facebook group members electronically signed a waiver, which provided an overview of the research project and disclaimers, then completed a screening survey via Qualtrics that required interested participants to select which option applied when asked about their age, education and income levels, and marital status. These questions, which can be viewed in Figure 2, were asked to assist me in creating focus groups that were diverse in each demographic. Location of residence was also confirmed, in efforts to pair individuals with the most appropriate focus group session. 
The in-person sessions consisted of 23 women in total (7 to 9 per group), who were asked 10 open-ended questions and engaged in discussion for no more than 60 minutes. Although 90-minute focus groups appeared to be a commonality among several focus groups, I elected to conduct 60 -minute focus groups considering my question count and participant maximum was lower.

To successfully conduct focus group interviews for my study, I utilized a wireless internet connection, social media, three separate gathering spaces (two conference rooms and one classroom), and a mobile phone on which each conversation was recorded. Each participant expressed interest in the subject matter through direct impact of heart disease (being or knowing of a loved one who has been diagnosed) or indirect impact (wanting to know more) when asked why they chose to participate in the research.

Interview questions, found in Figure 1, were inspired by previously published research. The types of questions asked were centered around sources of health information, inclusive of traditional media outlets and newer technology-based platforms.

The results build upon previous research of platforms utilized by Black women seeking health information and are reflective of the more technologically savvy world we have become. A small portion of the findings also contribute to what is known among the African-American female population about heart disease.

\section{Focus Group Discussion Guide}

A discussion guide inclusive of an introduction and conclusion script was used during each focus group session, as well as prompts for questions the participants were asked. My strategy in getting everyone involved in the conversation was to first let participants know that the focus group discussion was designed to assess their current 
thoughts, feelings, opinions and perceptions about using social media when seeking health information, and confirm their answers would be kept anonymous. I set the following ground rules: everyone's opinion is valuable, thus participation is encouraged; differing thoughts are welcome, but should be shared in respectful taste; and to not worry about disagreements because there are no right or wrong answers, as diversity of opinion can enhance research findings or prompt other participants to leave thinking about something differently.

During focus group sessions, there were some who dominated the conversation and others who were shy in their participation. For those who were more vocal in the discussion, my strategy was to light-heartedly call by name those who had not shared as many thoughts and mention my curiosity in hearing what their opinions were on a question (Krueger \& Casey, 2014). This statement was made immediately following the asking of the focus group question, so as to not give way to the ones who were dominating the conversation.

Some participants strayed off-topic when expressing their thoughts in response to a question. To bring them back on-theme, I mentioned one or two points within what participant shared that related to either social media, credibility or health information, and repeated the relevant question of discussion (Krueger \& Casey, 2014). Rephrasing their statement in this fashion conveyed my attentiveness to their comments and confirmed that I understood what they were saying, while simultaneously driving the discussion back on track.

Participant confidentiality was maintained by communicating about the study via emails to all selected participants individually. The Facebook group for recruiting was 
closed and no personal information was collected since members were not privy to know who was ultimately selected for the study. It was impossible to protect identities during each group interview, as they occurred in-person. However, I believe the direct interaction enhanced my findings and created an environment for more dialogue to take place. When citing evidence in findings, I specifically cited what a person said by using a unique identifier created after the data collection process. For example, if Jane Doe is J1, when referring to her comments, I would list "J1."

Interview best practices hone in on treating respondents as human beings and establishing a rapport with them, in efforts to make them comfortable and foster an environment where empowering narratives of multiple voices can occur. Brennan (2012) quotes Barbara Walters who notes that a conversation should involve both parties (interviewer and respondent) showing genuine interest, as well as a having a chance to express themselves in a way that is respected. Fontana and Frey (1994) posit the way an interviewer presents themselves has a "profound impression on respondents and has great influence on success or failure of study" (p. 367).

A potential pitfall that may have arisen, unbeknownst to me, when gathering data is a participant not providing their honest opinion in response to a question or being influenced by the thoughts of a dominant speaker or the majority of the group. In efforts to mitigate this issue, as an interviewer, I took an active role in managing the flow of the discussion to ensure everyone had a chance to speak and invited opposing ideals.

\section{Strategy for Analyzing Data}

Each focus group interview was transcribed verbatim to ensure accurately represented data. During the discussion, any uncertainties about what a participant was 
trying to imply or times when I found myself making a mental inference, there were certain questions I asked to probe for more explicit responses. This helped keep results and interpretations connected to each person's reality.

After verbatim transcriptions of the interviews were produced (Beal, 2015), data was analyzed by themes that arose during each focus group session (Rennis, McNamara, Seidel, \& Shneyderman, 2015; Bellinger, Millegan, \& Abdalla, 2015). The constructivist methodology was followed from that point, forward. Warren et al. (2010) describes this process as one that "understands experience (e.g., patterns of relationships, interactions, behaviors, cognitions and belief) is contextualized, socio-culturally constructed, and based on individual perception" (p. 75). The authors note that it begins by listening to the thoughts of the focus group participants and grasping the concepts of their perspectives enough to categorize them thematically. After main categories are created and coded, subcategories are derived and critically analyzed to ensure related concepts are linked and then placed under overarching themes. Unique responses were highlighted in the thesis discussion section.

It was interesting to observe the various demographics of participants, as well as any similarities or differences in the themes shared while comparing, contrasting and grouping responses. Based on comments about heart disease and health-related information African-American women seek and frequently depend on to learn more about the "silent killer," I was able to analyze common themes as to why there was not a sole reliance on Facebook or Twitter, but some perceived credibility in these platforms. 


\section{Chapter 4: Analysis/Results}

A sample size of 23 women, who each self-identified as being both Black and female, participated in three focus groups across both rural (Thomasville) and urban areas (Greensboro and Durham). The specific demographic information, collected from the Qualtrics screening survey each participant completed, can be found in Figure 3. Thirty-five percent of the women were between ages 25 and 34, and another 35 percent were between 55 and 64 . An average household income of $\$ 100,000$ was listed by 30 percent of participants, while another 30 percent was $\$ 25,000$ to $\$ 49,000$, and 4 percent listed their income as less than $\$ 25,000$. Of the participants, 48 percent held a master's degree and only 8 percent had some high school or less. Fifty-two percent were married, 26 percent were single, 18 percent were divorced and 4 percent were widowed.

It is important to understand the breakdown of each focus group, as concepts for two of the recurrent themes were likely influenced by the demographics within individual focus groups. Thomasville is a rural area and the majority of participants were between the ages of 35 and 44 years old, had at least some college education, and reported having an annual household income of $\$ 25,000$ to $\$ 49,999$. The majority of participants living in the urban city of Greensboro were the youngest of the three groups-ages 25 to 34 years old, yet held a master's degree and annual household income of $\$ 75,000$ to $\$ 99,999$. In the final urban location, Durham, over half of the participants fell in the 55 to 64 years old age range, making them my oldest group, held master's degrees and reported an annual household income of over $\$ 100,000$. 
Focus group sessions were transcribed verbatim, with unique identifiers serving as a coder for each participant to keep their comments confidential. The transcription was stored in a password protected application called Evernote. Each group conversation sought to answer the research questions:

RQ1: How do African-American women perceive Facebook as a source for heart disease information?

RQ2: How do African-American women perceive Twitter as a source for heart disease information?

As a result, my research uncovered that the subset of African-American women selected for each of my three focus groups perceive both Facebook and Twitter as credible sources of information about heart disease, and health in general, if the material shared comes from a health care professional or organization, or a friend speaking from their personal health experience. More notably, the credibility increases if the information is presented by a person of color-particularly of the same race. They also perceive Facebook and Twitter to be sources that require fact checking, thus prompting further research using a tool or website that is established within the health care industry.

Although the conversation focused on participants using these social media platforms to seek information on cardiovascular disease, it deviated into the territory of seeking general health information. Onward, the groups blended the two health topics in their responses to discussion questions. At times, I would have to add a prompt to a question that sought to understand the quest for heart disease information. For example, "there seem to be few responses. Talk to me about whether this is because you are not 
seeking heart disease related information, and if so, how does it relate to you looking for general health information?"

Sixty-five percent of focus group participants attributed their interest in being a part of the focus group was related to personally knowing someone impacted by heart disease-whether themselves or a loved one, and 83 percent expressed genuine interest in wanting to know more about heart disease and best practices for using social media to seek health information. These answers were in response to the first question listed in the discussion guide. It was interesting that, though such a large percentage of them were within two degrees of separation from cardiovascular disease, the conversation shifted towards more general health information seeking than CVD.

Five key themes consistently arose across each focus group session: perceptions of Facebook as a source for health information; perceptions of Twitter as a source for health information; posts on Facebook/Twitter prompting further research; advocating for one's own health; and the need for fact checking health info and professionals.

\section{Perceptions of Facebook as a Source for Heart Disease Information}

Of the Facebook users across all of the focus group members, 20 self-reported using it daily and 3 people reported using it weekly according to the Qualtrics screening survey results. Over half of the participants noted that this platform could be considered a credible source for heart disease or health information if the messenger was experienced in the health care industry or a friend speaking from their personal experience. When asked what makes a source credible, responses included that it is peer-reviewed, trustworthy, reputable, has credentials, or is referred. One participant noted that she 
aligned credibility with a confident answer and a couple members of the focus group agreed.

"I would say institutional knowledge. If you're new, I'm going to look at you [with doubt]. But, there are some hospitals that are reputable, so I'm going to look at them and those who say they're affiliated with [the organization sharing the information]. I'm going to want to know something about their credentials before I give it credence." [D1]

"When I'm seeking a service, or exploring a credible source for health concerns that I have, I'll check with people I trust and who I know experienced [what I'm going through] for referrals. I'll ask, 'have you been to this type of doctor? Would you refer them?"' [D5]

"To me, it's giving an explanation that you're not hesitant to believe. A confident answer gives credibility to me. If it sounds like you know what you're talking about, it's good... I'm willing to go with it." [T1]

These replies align with the aforementioned definition of credibility that was selected for my thesis, which was a combination of Spence et al. (2013) and van Zoonen and van der Meer's (2015) definition. To the authors and focus group participants, a perceiver would deem information credible if the source was trustworthy, an expert in the industry of the subject matter, and if the information seeker felt the content was communicated with accuracy and compassion.

Only 6 of the 23 participants gave a numerical rating to the level of dependability they associated with retrieving health information from Facebook. During each discussion, they were asked to give a rating of the platform on a scale of 0 to 10 , with 0 being no trust at all and 10 being the highest. Although a low percentage of women provided a rating, there were no rescinds about Facebook not having any credibility 
during the dialogue. The platform was at least used as a starting point to seek out additional information from more reputable health-related resources.

There were mentions about reliability depending on who posted the heart disease or health information; who the original source of a shared article or piece of information was; and whether they are peer-reviewed or reputable. Another common response was that trusted health information could be found by following the Facebook fan page of an accredited group such as the American Heart Association or a professional within the health care industry. Some individuals recalled posting inquiries about a remedy for a medical-related situation in their personal status on Facebook, and calling for those whom they are connected with on the platform to respond with their individual experiences or recommendations. Several women also noted that they learned new information about heart disease or health in general from groups targeting specific them as a Black woman or mom.

"I've joined certain Facebook groups because there are people in there who are people of color and they tend to source and link things that directly relate to people of color." [G1]

On the contrary, a few women voiced opinions that indicated they were less trusting of Facebook now than when the platform first launched, and noted that fact checking is of the utmost importance. There were comments that well-branded medical professionals (i.e., Dr. Oz) now seem to push out content or endorse products that will generate more engagement on Facebook and revenue for their brand instead of genuinely wanting to help the public.

"For me, it's more of like a need [for Facebook] to fact check because when I get information, I have to go and fact check it myself. I have to find something credible that I can go and look at. If they made it a requirement for Facebook, that if you're putting this information out there it has to be checked before you can 
post it, I wouldn't feel this way. For example, here's the information I'm posting and here are my sources. Otherwise, it could be marketing or something because anybody can post anything on Facebook." [G3]

\section{Perceptions of Twitter as a Source for Heart Disease Information}

According to the Qualtrics screening survey results, 20 focus group participants reported using Twitter weekly and the remaining 3 reported using it daily. This was the second highest social media tool used, in general, not specifically for seeking health information. Like Facebook, this platform was deemed a credible source by the majority of focus group participants who were Twitter users, provided that the messenger was someone in health care industry or a friend speaking from their personal experiences.

A few additional words to define credibility of a source, given by the women across all groups, were: one that has proven results, institutional knowledge, being dependable or experienced, or reliable. These words are in tandem with the Spence et al. (2013) and van Zoonen and van der Meer's (2015) combined definition of source credibility elected for this thesis. Only 3 women provided actual numbers when asked during the discussion to rank the level of trustworthiness of Twitter for heart disease and/or health information (which is half the number who ranked Facebook) on a scale of 0 to 10 with 10 being most and 0 being not credible. Although a low percentage of women provided a rating, there were no rescinds about Twitter not having any credibility during the discussion. The platform was not used as a be all and end all for health information, but at least served as a starting point to seek further information from more reputable health-related outlets.

"I give it about a 10 because I find more credible sources on [Twitter]. Like, if I'm looking for a particular article or something that's trending in the news, I find Twitter to have more of your journalists and celebrities and people like that. ... I don't follow a lot of personal accounts, I follow more like reputable, credible 
people. And to me, breaking news always breaks out on Twitter before everywhere else." [D2]

Similar to a concern with Facebook profiles, a participant voiced their skepticism about a rise in "spam" accounts, or profiles that appear to be designed to provide helpful, accurate information to the public, but actually share unreliable news or be sales-driven, on Twitter.

"I use [Twitter] maybe once a month now, but when I look at what comes up in that feed, I'll be honest, [I rate it] about a 6 . I do follow some health care organizations or professionals, but there are also people who throw up a page saying, "I'm health care disparities [dot] so and so" and I'm like, "who are you?" There are "fake news" accounts who are setup as marketing tools to make it look like they're really providing you with good health care information when really they're out there for other things or are bots." [D6]

A significant number of focus group participants in the urban cities cited that the validity of health information retrieved from both Facebook and Twitter increased if it came from someone who "looked like them" or was a person of color.

"The sources I rely on for health information are people of color and they tend to source and link things that directly relate to people of color." [G1]

"I think sometimes we believe among our own ethnicity. When I'm in a group with a whole lot of [Black people], we understand and we identify. Sometimes we're a lot more trusting of that particular website when the people talking to us who are credible (i.e., a Black physician talking about OB-GYN care or telling me about things on breastfeeding or chronic disease or getting my health together or losing weight), you know?" [D6]

"When I was pregnant with my youngest son, I was in a lot of pregnancy groups and afterwards, there was one called Supporting Black Moms Who Breastfeed. I didn't realize how high your chances are of getting congestive heart failure are when you're delivering. ... I had no clue because my doctor never brought those things up. It was important that I was in the Facebook group that was targeting Black moms.”[D2] 
The final two comments sparked sidebar conversation within one of the focus groups, which led me to ask the group whether credibility was impacted by someone who looked like them and talked their language. Five of the seven participants in that particular session agreed and no one had a rebuttal. This topic did not arise in the Thomasville focus group, but someone did mention that visuals added a level of credibility to health information viewed on Facebook or Twitter.

A participant who lived in one of the urban cities and was a health care professional added to the discussion that the U.S. Food and Drug Administration was inprogress of implementing mandates requiring a certain percentage of African-American participants in research, so the results are more inclusive. Such a change could benefit the population, as a larger sample size may reveal more effects of certain medications or research, in general.

\section{Facebook and Twitter Posts Prompting Further Research of Heart or Health Information}

Another theme that arose in the conversations with women who live in both rural and urban areas, was being inspired by posts on Facebook and Twitter to search for heart disease and other health information outside of the platforms. Figure 4 displays heart disease-related factors participants recalled gathering from the top two social media platforms. Most frequently mentioned topics of information include: awareness about heart disease and related conditions; risks factors such as stress and certain medications; preventative measures such as diet, exercise and heart examinations; and statistics on people impacted the most by heart disease. 
Participants relied on dialogue about other people's experiences or health challenges shared via Facebook or Twitter, especially if they or a loved one were going through something similar, then took that information to an even more reliable information (i.e., Mayo Clinic, health practitioner).

"I don't go to social media for any information. If I do find it there, I find myself taking it to Bing, Google or WebMD to vet what they're saying. If I can find other sources of truth, then I will share it with other people. But I don't use social media for that purpose." [G9]

"For someone to post any type of health information, it's an eye grabber. So, I open it up and look at it more in-depth-the words they're saying about it, if people start commenting and I start reading more into it, then I'll go search it somewhere else. Especially if it's something pertaining to myself. I read it and take it with a grain of salt then go to a more credible source to check it out." [T3]

In each of the three focus groups, it was mentioned and verbally agreed on by the majority of remaining participants, that both social media outlets were not the first place of research for heart disease or health information. However, personal statuses and health care articles shared prompted them to want to learn more and seek corroboration via outside sources, including their physician.

"I've seen friends on Facebook post something concerning a situation they're going through and I'll realize, "I'm going through the same thing," and then I'll contact them to get information about what they're going through to see if maybe I should go see this doctor or that doctor. Sometimes I'm not necessarily seeking it out, but if I see something pop-up in my news feed that relates to something that I'm going through, then I'll communicate with that friend or figure out what I can do to help my health." [G4]

References for primary care doctors or specialists, as well as specific medications, were also recommended and trusted via posts on the two social media platforms by their friends. A few participants added that heart disease or health information that was not widely known caught their attention. 
"I saw something on Facebook about what to do if you think you're having a heart attack and you were alone-about coughing and taking deep breaths, and I was like, "really?" That's something I learned on Facebook. I live by myself, so I now know what to try if that's the case." [T7]

"I found information on Facebook about taking a Bayer aspirin to help with the possible risk of having a heart attack or helping with your blood flow. That's one thing I take into consideration." [T1]

Dialogue about online tools frequently used for seeking health information sparked a lot of interest. Only one of the Thomasville participants noted that an established source was preferred over a Google search. She had experience in the medical field. The remaining majority appreciated being able to sort through a myriad of options and opinions or explanations. They also found those results to be easy to understand.

"I would try to go straight to a source related to the issue I'm looking up where more studies and more accurate information is recorded and reviews of different medications and different things people are using, different diagnoses [can be found]. With Google search, no offense ladies, you get a lot of opinions. And, to me, what affected me, may not affect you, so why should you take my information and say "oh, this is what's going to be wrong with me." For example, if I was put on an antibiotic for 7 days and you were put on it and it didn't work for me, that doesn't mean it's not going to work for you. I might need a 10-day course, or a 14-day course, whereas 7 days may take care of you. Everybody's body makeup and physical chemistry isn't the same. Google to me is a lot of opinions, whereas going straight to the source, like American Heart Association, is recorded data of a lot of different people and from a lot of standpoints instead of one person's opinion." [T4]

"See, I like Google search for that very reason. I get to choose. I get to read different information and form my own opinion and not feel like it's structured. Like she's giving her own opinion, she's giving her own opinion. Whereas, sometimes my opinion is when we go to specific sites or whatever, they give you what they want you to hear or modify/adjust it to fit whatever it is they want you to do. You have to incorporate all resources. Google gives you several articles to choose from and you can say, "okay this one makes sense." [T6] 
In contrast, the majority of both Greensboro and Durham participants sought established sources (i.e., Mayo Health Clinic, Cleveland Clinic, peer-reviewed research, the State department's magazine- N.C. Smart Health) and admitted to shying away from the use of a large search engine. Two opposing statements on this topic coming from each of the urban locations stood out most:

“... I [prefer to] use social media. When I was pregnant, I would ask other moms questions about things on Facebook or I would post, "to all the moms, this is what's going on, what did you experience," and people would just comment, so I guess it wasn't seeking medical professionals, but just asking people that had been through the same things." [G2]

"I mean we live in [Durham,] an area that's very health care rich from pharmaceutical companies to large health care providers and hospitals and institutions. Might there be an advantage where we have a little more forethought on our minds when seeing a commercial on TV or our Facebook feed for trials or studies, or because we hear more about it than we might if we weren't in an environment such as the one we are privileged to be in? When you think about some of the health care that a Duke or UNC provides, people travel across the country to access it depending on what that specialty is." [D7]

The latter comment piqued my interest most. Could it be that because participants who lived in the urban locations are surrounded by more established health care organizations, that the preference for heart disease or health information to come from a distinguished platform, and not a search engine, exist?

\section{Advocating for One's Own Health}

The importance of using heart disease or health information found online (web or social) and advocating for one's own health was another common theme. One participant mentioned a medical technology device that captures blood pressure diagnostics reading that her vitals were high, but she did not feel any different. Soon after, her job held a biometric screening and when they used a manual pump, her blood pressure read normal. 
This prompted her to have her doctor's office follow the same procedure during her next visit and it has read normal ever since. Had she not prompted them to do so, she likely would have been prescribed medication to regulate her seemingly high blood pressure.

"I've learned from being involved in health care from the patient side a lot, that you have to be your own advocate with doctors, hospitals. You have to ask a lot of questions. You can't take anything anyone says as golden, even if their good. If you believe they're good, you still have to do some extra work. I'll ask my doctor sometimes if something is going on, via Duke MyChart, and ask a question and when he comes back with the answer, I'm like "hmm and I'm going to go to WebMD or somewhere to verify." [D4]

"You know your body. Years ago, I was having problems with getting up in the morning and passing out - not knowing what was going on, having a bunch of different symptoms. I got to the doctor and they told me nothing was wrong with me and I'm like "how is something not is wrong with me?" I'm young. I'm not supposed to be getting up and then pass out. I told [a new] doctor, "well I saw this on WebMD and these are the symptoms I'm having and she agreed, then ran some tests to be sure." [T6]

"I don't think the doctors like for you to question them or ask a whole bunch of questions. I used to never go to the doctor, but now I go with questions like, "well why do you do this and why is it this?" ... If it doesn't make sense to me, I'm going to ask my questions and even when he says, "well I'm the doctor," I'm like "well, yeah you are, but why don't you [ever recommend] something preventative?" [T7]

The topic was only discussed among the Durham and Thomasville focus group participants, which led me to wonder if age was a factor. Greensboro had the youngest mean age, so perhaps more youthful participants had not experienced a health issue where the need to advocate for themselves arose.

\section{Need for Fact Checking Health Information and Professionals}

Though Akerkar \& Bichile (2004) mention that only 25 percent of health information seekers check the source and timeliness of information they find on the internet, I was not surprised by the significant amount of mentions about fact checking 
information found on social media. The majority of participants held a master's or bachelor's degree, and according to research by Helsper \& Eynon (2010), a strong educational background was positively aligned with a person's "use of the internet for fact checking and training and learning" (p. 517). The authors used data collected from a sample survey about internet users, why they use it (which included searching for health information), its impact on their daily lives, and used the information to make distinctions between the varying levels of comfortability with the internet.

"For me, I would have to be able to do a deeper research on the person giving the [health] information, so I'm going to google their name, then their organization until I really find out that this is a legitimate person and organization before I trust anything s/he is saying." [G8]

"There are so many spam accounts and psychos and stuff [on Facebook], I feel like it'll be taking a chance [to not fact check], unless you know the person who wrote the article, that it's a marketing firm or is completely outdated or some crazy stuff to try." [G2]

A few focus group participants noted that doctors received a kickback from pharmaceutical companies, so there was caution in always taking what is prescribed without asking questions and doing research on the drug and non-medicinal treatments. Comments were also mentioned during focus group discussions that as AfricanAmericans, at times, the body's response to medications can differ than non-Black counterparts. The same reservation was voiced by those who were recommended to have certain medical procedures. 


\section{Chapter 5: Discussion/Conclusions}

The results of this study indicate that Facebook and Twitter are perceived as credible sources for heart disease information among the African-American women who participated in each of the three focus groups. Over half of the participants, at some point during the focus group, mentioned gathering health information from posts on both platforms-whether via a friend they are connected with on social, a nationally respected health care organization, a health-related online social group they were a member of, or the responses to a health question they personally posted. The Black women in this study largely deemed knowledge gained via social media to be the spring board to further research about heart disease or another health concern. They were also passionate about the importance of advocating for one's own self in the doctor's office and why fact checking health information and professionals is of the utmost importance.

My research was designed to contribute data that can be used to improve health communication, in order to increase awareness about cardiovascular disease among African-American women and provide additional education tools for preventative and coping measures that can be taken. Findings expanded on previous research involving the search for health information by Black women across communication media. By uncovering that Black women perceive Facebook and Twitter as credible sources that disseminate information about heart disease, with Facebook being deemed the most reliable, health professionals can consider focusing on this platform when strategizing where to place content. 
During a CBS News (2017) interview, cardiologist Tara Narula shared that women (in general) had misconceptions about heart disease including a certain age one needed to be, one's overall health condition, and their likelihood of being diagnosed (i.e., if I don't know anyone who has heart disease, I'm not as concerned about being diagnosed with it). It is clear that unknown facts about heart disease need to be clarified and myths dispelled, to increase awareness. Once health messages to increase awareness and better educate are formulated, then the media dependency theory can be used to provide context around where to put the messages, so that they are received.

Uses and gratifications theory takes a deeper dive into the motivations for why this population actively seeks information on heart disease via the aforementioned outlets. Media systems dependency guides efforts to understand how often the named communication media are used. Understanding why and how frequently Facebook and Twitter are used helps gauge the level of credibility these sources have among the targeted population.

A veridicality effect, or "perception of an object as being accurate and believable regardless of the source" (Lee, Park, Lee, \& Cameron, 2010, p. 310), also seemingly comes into play based on the results that include some focus group participants relying on health information retrieved via search engines or posts on Facebook and Twitter. The authors describe the effect as one perceiving information to be credible that is "well produced and believable" (p. 312). In past times, a source delivering a message would have to be highly credentialed in order to be trusted. The present new media age has opened the information sharing space up wider, making it more difficult for audiences to discern who is truly the messenger, and whether they are qualified to deliver the message. 
Those in the new media space are also using the latest technology to make messages more appealing from a visual perspective, thus increasing naivety. If social media users do not exercise proper discernment in fact checking, they could run the risk of reading and spreading misinformation.

\section{Limitations}

Although uses and gratifications and media systems dependency serve as the theoretical frameworks of choice for this study, there are limitations within each theory as they relate to the retrieval of health information by African-American women, as well as their dependency on and confidence in certain communication media.

Media dependency focuses on one's reliance on information systems rather than how consumers' knowledge is increased and how it helps them act on the information in ways such as engaging in more meaningful physician-patient communication (Len-Ríos, Cohen, \& Caburnay, 2010).

Len-Ríos (2009) highlights another limitation that my research did not address. She states that mass media are effective at making consumers aware of information, but not much is known about how repeated exposure to messages over time can influence health behavior or how information from media is spread through social networks and word-of-mouth.

Chisolm and Sarkar (2015) address hindrances with the internet being a source of health information and this limitation also applies to my research. The authors note that finding high-quality sites can pose a challenge to health information-seekers, with some sites offering incomplete and inaccurate information. Additionally, their research mentioned the concern of potential users lacking health literacy and not evaluating what 
websites are appropriate to rely on or even how to implement the recommendations they find. These issues were acknowledged multiple times during each focus group conversation. However, a few participants were able to share reliable sources and what characteristics made them credible, as well as uncover concerns with some resources mentioned that were questionable.

Online health information can be particularly appealing and advantageous to populations for whom access to a medical specialist is a challenge. However, there are patients who felt that "using health information from websites to influence decisionmaking, without guidance from experts, could potentially have an adverse effect on their health" (Chisolm and Sarkar, 2015, p. 168). The survey research was designed to observe the health information seeking behaviors of Black women, but the mentioned apprehension indirectly uncovered a portion of the thought process participants went through when determining the trustworthiness of a site.

This research was solely conducted in North Carolina, which is only one of the 50 U.S. states. There is a possibility that findings would be different had focus groups been conducted in multiple states located throughout the nation (i.e., Northern or Western states) or additional cities within North Carolina.

Not requiring each focus group participant to rank the level of credibility for both Facebook and Twitter created another limitation. There were less than seven responses when the question was asked to provide a number on a scale of 0 to 10 , with 10 being most and 0 being not credible, that describes their perspective of each platform's reliability. 


\section{Areas for Further Research}

Implications for further research arose from certain responses to my interview questions about what the focus group has learned about heart disease from Facebook and Twitter, as well as my inquiry for the group to share anything that came to mind that was not asked. The most common area was how Black women respond to health (including heart disease) messages and advertisements delivered by African-American women, or women of color, as opposed to ones visually coming from other races (specifically Caucasian).

Several participants mentioned motivators for joining private and public groups on Facebook were that the messages targeted Black people, especially women, and that people of color were presenting information that directly relates to or impacts them. More research could be done in exploring the reasoning behind the aforementioned preference and whether it connects back to the Tuskegee Syphilis Study, which is widely known for playing a role in the mistrust African-Americans have towards medical and public health organizations (Gamble, 1997).

Continuing this line of study in heart health as it relates to African-American women is valuable. One of the focus group participants mentioned being inundated with information between health fairs sponsored by organizations (i.e., work, church) and social media campaigns. She acknowledged that they both garner a significant level of engagement, but questioned whether women were listening to take action, or just hearing what was being said. Further research in the areas of tailoring messages on social media and gauging their effectiveness in prompting health behavior change would be ideal in addressing the noted concern. Considering 65 percent of focus group participants were 
impacted by heart disease in a personal way (self or loved one), which aligns with the fact that Black women are the largest population affected by CVD, perhaps including family member names (i.e., mother, aunt, grandmother) in the messages and testing how well it is received may be worth exploring.

Another area for additional exploration is comparing health information seeking behaviors among Black women who live in areas populated with numerous health care facilities and institutions versus those who have a significantly smaller amount, if any at all. A few focus group participants mentioned that living in a place coined as the "City of Medicine" could have unique advantages in that their population does not have to search far for reliable health information. Also, there are a large variety of resources and specialty practices within their community that otherwise do not exist in smaller, or more rural areas.

Former research did not thoroughly cover how Facebook and Twitter prompts patients to put information learned into action such as having preventative screenings conducted, enhancing the conversations they have with their health care providers, or altering eating and lifestyle habits. Evaluating effectiveness of health information, heart disease awareness in particular, that is disseminated via social media was a unique topic discussed in one of the three focus groups. A participant mentioned that, at times, she felt inundated with information to process and wondered if others experienced the same feelings. This overload was mentioned to take place most frequently on social media and at health fairs. A tool to mark outcomes or evaluation system would first need to be devised that could better gauge whether awareness and preventative measures shared prompted health behavior changes. It would likely be more feasible to conduct such an 
assessment after a global or national awareness day campaign (i.e., National Wear Red Day).

According to Parker and Thorson (2009), "health systems and providers who are willing to accept digital and electronic media applications are likely to find improvements in patient satisfaction, market share increases, and perhaps enhanced health among patients" (p. 432). For example, some health care organizations have created mobile applications that allow patients to perform functions such as scheduling appointments, reviewing test results, requesting a prescription refill and sending a direct message to their provider, to name a few. This could be a possible area for greater exploration, as more health organizations tap into mobile applications and other creative ways of disseminating health information via technology. 


\section{References}

Anderson, M., \& Perrin, A. (2016, September 7). 13\% of Americans don't use the internet. Who are they? Retrieved July 19, 2017, from

http://www.pewresearch.org/fact-tank/2016/09/07/some-americans-dont-use-theinternet-who-are-they/

Ball-Rokeach, S. J., \& DeFleur, M. L. (1976). A Dependency Model of Mass-Media Effects. Communication Research, 3(1), 3-21. https://doi.org/10.1177/009365027600300101

Barthel, M., Shearer, E., Gottfried, J., \& Mitchell, A. (2015, July 14). News Use on Facebook and Twitter Is on the Rise. Retrieved October 7, 2017 from http://www.journalism.org/2015/07/14/news-use-on-facebook-and-twitter-is-onthe-rise/

Bates, B. R., Romina, S., Ahmed, R., \& Hopson, D. (2006). The effect of source credibility on consumers' perceptions of the quality of health information on the Internet. Medical Informatics \& the Internet in Medicine, 31(1), 45-52. https://doi.org/10.1080/14639230600552601

Beal, C. C. (2015). Stroke Education Needs of African American Women. Public Health Nursing, 32(1), 24-33. https://doi.org/10.1111/phn.12158

Beaudoin, C. E., Fernandez, C., Wall, J. L., \& Farley, T. A. (2007). Promoting Healthy Eating and Physical Activity: Short-Term Effects of a Mass Media Campaign. American Journal of Preventive Medicine, 32(3), 217-223. https://doi.org/10.1016/j.amepre.2006.11.002

Bellinger, J. D., Millegan, W., \& Abdalla, A. E. (2015). "I'm Not Ashamed to Talk on It!": African-American Women's Decisions About Cervical Cancer Prevention and Control in South Carolina. Women's Health Issues, 25(2), 120-127. https://doi.org/10.1016/j.whi.2014.10.006

Berger, Arthur Asa. (1998). Media Research Techniques, Second Edition. Sage.

Brennan, Bonnie. Qualitative Research Methods for Media Studies. Routledge 2012

Burrell, T. J. (2000). Make it personal. Advertising Age, 71(7), s18.

Campbell, K. (2016). Gone in 80 seconds - Women and heart disease. U.S. News \& World Report. Retrieved from http://health.usnews.com/health-news/patientadvice/articles/2016-02-12/gone-in-80-seconds-women-and-heart-disease 
Chen, C.-Y., \& Chang, S.-L. (2017). User-orientated perspective of social media used by campaigns. Telematics and Informatics, 34(3), 811-820.

https://doi.org/10.1016/j.tele.2016.05.016

Chisolm, D. J., \& Sarkar, M. (2015). E-Health Use in African American Internet Users: Can New Tools Address Old Disparities? Telemedicine and E-Health, 21(3), 163169. https://doi.org/10.1089/tmj.2014.0107

Fontana, A. and Frey, J. H. (1994). Interviewing: The art of science. In the Handbook of Qualitative Research, edited by N. Denzin and Y. Lincoln. Thousand Oaks: Sage Publications. (pp. 361-376)

Gamble, V. N. (1997). Under the shadow of Tuskegee: African Americans and health care. American Journal of Public Health, 87(11), 1773-1778.

Greenbaum, T. L. The Handbook for focus group research. NY: Lexington, 1993

Hall, I. J., Ashani Johnson-Turbes, C., \& Williams, K. N. (2010). The Potential of Black Radio to Disseminate Health Messages and Reduce Disparities. Preventing Chronic Disease, 7(4). Retrieved from http://www.ncbi.nlm.nih.gov/pmc/articles/PMC2901585/

Helsper, E. J., \& Eynon, R. (2010). Digital natives: Where is the evidence? British Educational Research Journal, 36(3), 503-520. https://doi.org/10.1080/01411920902989227

Kaye, B. K., \& Johnson, T. J. (2016). Strengthening the Core: Examining Interactivity, Credibility, and Reliance as Measures of Social Media Use. Electronic News, 1931243116672262. https://doi.org/10.1177/1931243116672262

Kim, J., Lee, J., Jo, S., Jung, J., \& Kang, J. (2015). Magazine Reading Experience and Advertising Engagement: A Uses and Gratifications Perspective. Journalism and Mass Communication Quarterly, 92(1), 179-198. https://doi.org/http://dx.doi.org/10.1177/1077699014559914

Krueger, R. A., \& Casey, M. A. (2014). Focus Groups: A Practical Guide for Applied Research. SAGE Publications.

Lachlan, K. A., Spence, P. R., Edwards, A., Reno, K. M., \& Edwards, C. (2014). If you are quick enough, I will think about it: Information speed and trust in public health organizations. Computers in Human Behavior, 33, 377-380. https://doi.org/10.1016/j.chb.2013.08.014

Laz, T. H., \& Berenson, A. B. (2013). Racial and ethnic disparities in internet use for seeking health information among young women. Journal of Health Communication, 18(2), 250-260. https://doi.org/10.1080/10810730.2012.707292 
Lee, H., Park, S.-A., Lee, Y., \& Cameron, G. T. (2010). Assessment of motion media on believability and credibility: An exploratory study. Public Relations Review, 36(3), 310-312. https://doi.org/10.1016/j.pubrev.2010.04.003

Len-Ríos, M. E. (2009). Communication strategies for reducing racial and cultural disparities. Health communication in the new media landscape, 41-58.

Len-Ríos, M. E., Cohen, E., \& Caburnay, C. (2010). Readers Use Black Newspapers For Health/Cancer Information. Newspaper Research Journal, 31(1), 20-35.

Lumpkins, C. Y., Cameron, G. T., \& Frisby, C. M. (2012). Spreading the Gospel of Good Health: Assessing Mass Women's Magazines as Communication Vehicles to Combat Health Disparities Among African Americans. Journal of Media and Religion, 11(2), 78-90. https://doi.org/10.1080/15348423.2012.688664

Ma, T. (J.), \& Atkin, D. (2017). User generated content and credibility evaluation of online health information: A meta analytic study. Telematics and Informatics, 34(5), 472-486. https://doi.org/10.1016/j.tele.2016.09.009

Matsa, K. E., \& Lu, K. (2016, September 14). 10 facts about the changing digital news landscape. Retrieved July 19, 2017, from http://www.pewresearch.org/facttank/2016/09/14/facts-about-the-changing-digital-news-landscape/

McCarroll, M. L., Armbruster, S. D., Chung, J. E., Kim, J., McKenzie, A., \& von Gruenigen, V. E. (2014). Health Care and Social Media Platforms in Hospitals. Health Communication, 29(9), 947-952. https://doi.org/10.1080/10410236.2013.813831

Mitchell, A., Gottfried, J., Barthel, M., \& Shearer, E. (2016, July 7). The Modern News Consumer. Retrieved July 18, 2017, from http://www.journalism.org/2016/07/07/the-modern-news-consumer/

Paige, S. R., Krieger, J. L., \& Stellefson, M. L. (2017). The Influence of eHealth Literacy on Perceived Trust in Online Health Communication Channels and Sources. Journal of Health Communication, 22(1), 53-65. https://doi.org/10.1080/10810730.2016.1250846

Parker, J. C., \& Thorson, E. (2009). Health Communication in the New Media Landscape. New York, NY: Springer Publishing Company.

Pauly, J.J. (1991) A Beginner's Guide to doing Qualitative Research in Mass Communication. Journalism and Mass Communication Monographs, 125, 1-29.

Pew Research Center. (2013). Health Online 2013, Pew Internet \& American Life Project. Retrieved from http://pewinternet.org/Reports.2013/Health-online.aspx 
Pew Research Center. (2017). Internet/Broadband Fact Sheet. Pew Research Center. Retrieved from http://www.pewinternet.org/fact-sheet/internet-broadband/

Rains, S. A., \& Karmikel, C. D. (2009). Health information-seeking and perceptions of website credibility: Examining Web-use orientation, message characteristics, and structural features of websites. Computers in Human Behavior, 25(2), 544-553. https://doi.org/10.1016/j.chb.2008.11.005

Rennis, L., Mcnamara, G., Seidel, E., \& Shneyderman, Y. (2015). Google It!: Urban Community College Students' Use of the Internet to Obtain Self-Care and Personal Health Information. College Student Journal, 49(3), 414-426.

Riffe, D., Lacy, S., \& Varouhakis, M. (2008). Media System Dependency Theory and Using the Internet for In-depth, Specialized Information. Web Journal of Mass Communication Research, 11, 1-14.

Rimal, R. N., \& Adkins, A. D. (n.d.). Using computers to narrowcast health messages: The role of audience segmentation, targeting, and tailoring in health promotion. ResearchGate. Retrieved from https://www.researchgate.net/publication/232602601_Using_computers to narro wcast health messages The role of audience segmentation targeting and tail oring_in_health_promotion

Ruggiero, T. E. (2000). Uses and Gratifications Theory in the 21 st Century. Mass Communication and Society, 3(1), 3-37. https://doi.org/10.1207/S15327825MCS0301_02

Sadler, G. R., Escobar, R. P., Ko, C. M., White, M., Lee, S., Neal, T., \& Gilpin, E. A. (2005). African-American women's perceptions of their most serious health problems. Journal of the National Medical Association, 97(1), 31-40.

Spence, P. R., Lachlan, K. A., Westerman, D., \& Spates, S. A. (2013). Where the Gates Matter Less: Ethnicity and Perceived Source Credibility in Social Media Health Messages. Howard Journal of Communications, 24(1), 1-16. https://doi.org/10.1080/10646175.2013.748593

Sundar, S. S., \& Limperos, A. M. (2013). Uses and Grats 2.0: New Gratifications for New Media. Journal of Broadcasting \& Electronic Media, 57(4), 504-525. https://doi.org/10.1080/08838151.2013.845827

Tillman, L. C. (2002). Culturally Sensitive Research Approaches: An African-American Perspective. Educational Researcher, 31(9), 3-12. https://doi.org/10.3102/0013189X031009003 
Tindall, N. T. J., \& Vardeman-Winter, J. (2011). Complications in segmenting campaign publics: Women of color explain their problems, involvement, and constraints in reading heart disease communication. Howard Journal of Communications, 22(3), 280-301. https://doi.org/10.1080/10646175.2011.590407

Tustin, N. (2010). The Role of Patient Satisfaction in Online Health Information Seeking. Journal of Health Communication, 15(1), 3-17. https://doi.org/10.1080/10810730903465491

U.S. Census Bureau. (2016). NC Cities/Towns Population Estimates, 2016 [Data file]. Retrieved from http://media2.newsobserver.com/static/content/multimedia/interactive/census/ncp opulation.html

van Zoonen, W., \& van der Meer, T. (2015). The Importance of Source and Credibility Perception in Times of Crisis: Crisis Communication in a Socially Mediated Era. Journal of Public Relations Research, 27(5), 371-388. https://doi.org/10.1080/1062726X.2015.1062382

Wang, Y., \& Rodgers, S. (2013). Reporting on Health to Ethnic Populations: A Content Analysis of Local Health News in Ethnic Versus Mainstream Newspapers.

Howard Journal of Communications, 24(3), 257-274. https://doi.org/10.1080/10646175.2013.805991

Warren, J. R., Kvasny, L., Hecht, M. L., Burgess, D., Ahluwalia, J. S., \& Okuyemi, K. S. (2010). Barriers, control and identity in health information seeking among African American women. Journal of Health Disparities Research \& Practice, 3(3), 6890. 


\section{Appendix A}

1. Please share a little bit about yourself, including why you decided to attend the group, if you have any loved ones who were or are impacted by heart disease, and your favorite color.

2. What social media platforms do you use and how often?

3. Not including your doctors and nurses, where do you most frequently go to get information about heart disease (i.e., health organization websites like Mayo Clinic or local hospital, a certain blog, email listserv, Facebook page of a news organization, etc.)?

Prompt: Not many have responded. Talk to me about whether it's because you don't look for heart diseaserelated information at all, and if that's the case, where do you go to look for health information in general?

4. For those who mentioned social media and non-social media sources they go to for heart disease-related information, why do you go to these sources?

Prompt: For those who mentioned that they don't look up heart disease information, why do you go to the sources you mentioned for general health information?

5. What is your definition of the word "credible?"

6. What makes you decide that the health information you read about on Facebook and/or Twitter is credible?

7. What have you learned about heart disease from something you saw on Facebook and/or Twitter?

8. How credible do you believe health information you see on Facebook to be?

Prompt: You can say not at all, rate it on a scale of 0 to 10, with 0 being not credible and 10 being the most credible, or say what aspects are credible and which aren't.

9. How credible do you believe health information you see on Twitter to be?

Prompt: You can say not at all, rate it on a scale of 0 to 10, with 0 being not credible and 10 being the most credible, or say what aspects are credible and which aren't.

10. What wasn't asked that you'd like to share?

\section{Figure 1. Selected Questions from the Focus Group Discussion Guide}




\section{Appendix B}

1. First and Last Name

2. Phone number (mobile preferred)

3. Email address

4. Age
a. $25-34$
b. $35-44$
c. $45-54$
d. $55-64$
e. $\quad 65-74$
f. $75-85$

5. Is your city of residence Durham, Greensboro, or Thomasville? Note: This study is only for residents of these cities.

6. Do you identify as Black/African-American?

7. Do you identify as female?

8. Marital status
a. Single
b. Married
c. Separated
d. Divorced
e. Widowed

9. What is your highest level of education completed?
a. Some high school or less
b. High School
c. Some college or less
d. Bachelor's
e. Master's
f. Doctorate

10. What is your income level?
a. Less than $\$ 25,000$
b. $\$ 25,000-\$ 49,999$
c. $\$ 50,000-\$ 74,999$
d. $\$ 75,000-\$ 99,999$
e. $\$ 100,000+$

11. How often do you spend one minute or more on Facebook?
a. 1-3 times per week
b. 4-6 times per week
c. Daily
d. More than 2-4 times per day
e. More than 5 times per day

12. How often do you spend more than one minute on Twitter?
a. 1-3 times per week
b. 4-6 times per week
c. Daily
d. More than 2-4 times per day
e. More than 5 times per day

\section{Figure 2. Participant Screening Survey via Qualtrics}




\section{Appendix C}

\begin{tabular}{|c|c|c|}
\hline Characteristics & & Total \\
\hline \multicolumn{3}{|l|}{ Race } \\
\hline & African-American & 23 \\
\hline \multicolumn{3}{|l|}{ Age } \\
\hline & 25 to 34 & 8 \\
\hline & 35 to 44 & 5 \\
\hline & 45 to 54 & 2 \\
\hline & 55 to 64 & 8 \\
\hline & 65 to 74 & 1 \\
\hline \multicolumn{3}{|l|}{ Education } \\
\hline & Some high school or less & 1 \\
\hline & High School & 1 \\
\hline & Some college & 5 \\
\hline & Bachelor's & 5 \\
\hline & Master's & 11 \\
\hline \multicolumn{3}{|c|}{ Income (U.S. dollars) } \\
\hline & Less than $\$ 25,000$ & 1 \\
\hline & $\$ 25,000$ to $\$ 49,999$ & 7 \\
\hline & $\$ 50,000$ to $\$ 74,000$ & 4 \\
\hline & $\$ 75,000$ to $\$ 99,999$ & 4 \\
\hline & More than $\$ 100,000$ & 7 \\
\hline \multicolumn{3}{|l|}{ Marital status } \\
\hline & Single & 6 \\
\hline & Married & 11 \\
\hline & Separated & 1 \\
\hline & Divorced & 4 \\
\hline & Widow & 1 \\
\hline
\end{tabular}

Figure 3. Demographic Characteristics of African-American Female Focus Group

\section{Participants}




\section{Appendix D}

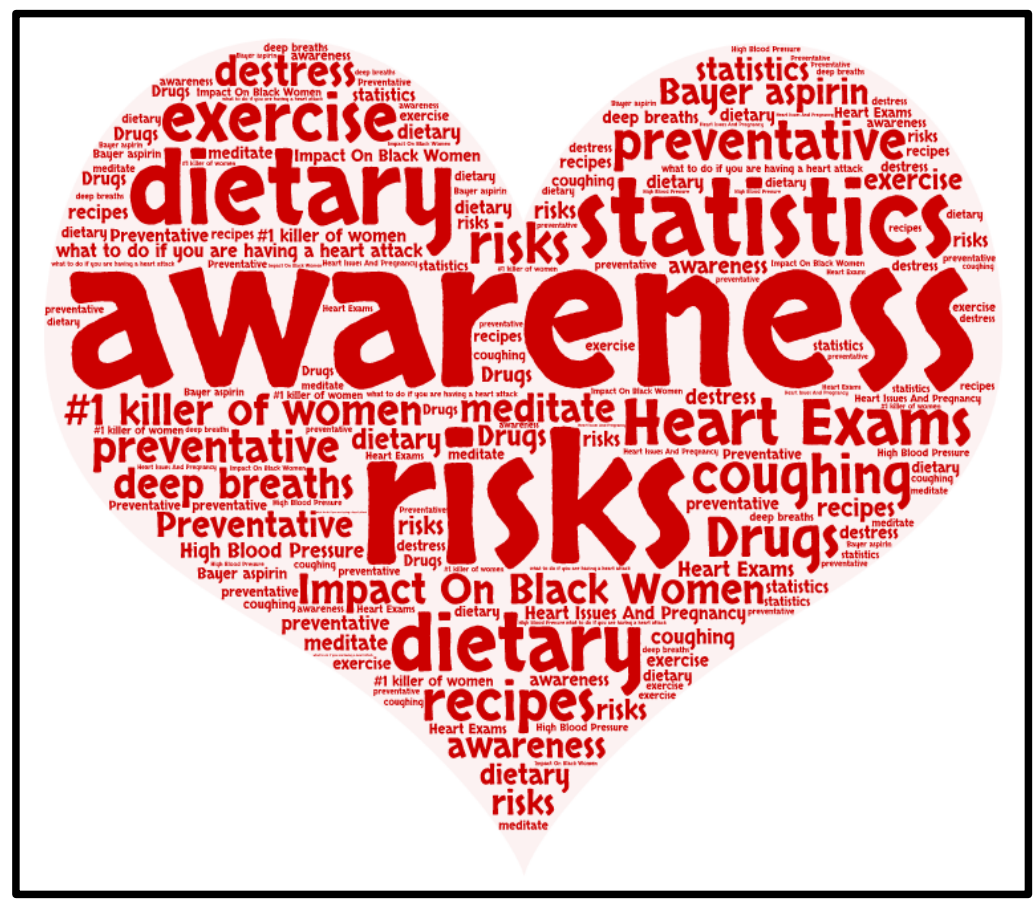

Figure 4. Heart Disease-Related Factors All Focus Group Participants Learned from

Facebook and Twitter. 